\title{
Development of Functional Diarrhea, Constipation, Irritable Bowel Syndrome, and Dyspepsia During and After Traveling Outside the USA
}

Ashok K. Tuteja $\cdot$ Nicholas J. Talley $\cdot$ Stephanie S. Gelman •

Stephen C. Alder · Clinton Thompson · Keith Tolman •

DeVon C. Hale

Published online: 2 August 2007

(C) Springer Science+Business Media, LLC 2007

Erratum to: Dig Dis Sci (2007)

DOI 10.1007/s10620-007-9853-x

The fourth author's family name was incorrectly published as Adler. The correct family name is Alder (as shown in this erratum).

The online version of the original article can be found under doi: 10.1007/s10620-007-9853-x.

A. K. Tuteja

George E. Wahlen V.A. Medical Center, Salt Lake City, UT,

USA

A. K. Tuteja $(\bowtie) \cdot$ S. S. Gelman · S. C. Alder ·

C. Thompson - K. Tolman · DeVon C. Hale

Division of Gastroenterology, University of Utah, 30 N 1900 E,

4R118 SOM, Salt Lake City, UT 84132, USA

e-mail: Ashok.Tuteja@hsc.utah.edu

N. J. Talley

Mayo Clinic College of Medicine, Rochester, MN, USA 